\title{
COMO PESQUISAR A EXPERIÊNCIA DO PÚBLICO EM EXPOSIÇÕES DE ARTE E TECNOLOGIA
}

Camila Damico Medina ${ }^{1}$

\section{Resumo}

Equipamentos culturais têm demonstrado ascendente interesse em assumir em suas programações exposições de arte e tecnologia. Esta tendência está vinculada ao processo de reformulação de seus modelos expográficos, em busca de maior inserção e participação do público nas instituições. Por conta disso, são observados mais projetos experimentais, que exploram alternativas disposições do público ao agenciar diferentes condições para visitação. Com este processo, é constatada intensa disputa sobre como o espectador deve apropriadamente se relacionar com as propostas artísticas híbridas. A partir da particular posição que ocupo como pesquisadora, procuro ao longo deste artigo verificar como construir uma escrita etnográfica deste contexto de reestruturação expográfica a partir da reconfiguração da experiência do espectador. Considero ao longo do texto como minha trajetória de planejamento da pesquisa e de entrada em campo pode contribuir para uma forma de estudo sobre as exposições de arte e tecnologia e sua absorção no circuito mainstream da arte.

Palavras-chave: Arte e tecnologia; Espectador; Participação do público; Expografia; Etnografia.

\section{How to research audience experience at art and technology exhibitions}

\begin{abstract}
Cultural institutions have shown an increasing interest to include exhibitions of art and technology in their programming. This tendency has been linked to a reformulation process of models of display, in search of greater insertion and participation of the public in the institutions. As a result, projects that are more experimental have been explored, as well as alternative dispositions of the public when different conditions for visitation are arranged. With this process, there is an intense dispute about how the spectator should appropriately relate to the hybrid artistic proposals. From the particular position that I occupy as a researcher, in this article, I try to verify how to construct an ethnographic writing of this context of exhibition restructuring from the reconfiguration of the spectator's experience. I consider how my trajectory of research planning and entry into the field can contribute to a way of studying art and technology exhibitions and their absorption in the mainstream circuit of art.
\end{abstract}

Keywords: Art and technology; Spectator; Audience engagement; Exhibition display; Etnography.

\footnotetext{
${ }^{1}$ Mestre em Comunicação e Cultura pela Universidade Federal do Rio de Janeiro, linha de pesquisa Tecnologias da Comunicação e Estéticas. Graduação em Produção Cultural pela Universidade Federal Fluminense. Complementou seus estudos em intercâmbio na Université Paris-VIII-Saint-Denis, onde cursou License em Philosophie.
} 


\section{Entrada de exposições de arte e tecnologia no circuito mainstream de arte}

O renovado interesse de equipamentos culturais ${ }^{2}$ no circuito mainstream de arte por exposições de linguagens híbridas ${ }^{3}$ está atrelado a uma ascendente busca pela diversificação de sua programação. A absorção de projetos que investigam as relações entre arte, ciência e tecnologia tem se inserido no processo de revisão das estratégias de comunicação destes espaços com o seu entorno. Este processo tem agenciado a desconstrução de uma hierarquia entre gêneros de expressão através de suas exposições - desarranjando lugares, comportamentos, técnicas, materiais e atores tidos como legítimos para a produção artística , como forma de atrair a frequência do público.

Por circuito mainstream de arte, tomo emprestado o conceito de arte mainstream articulado por Edward Shanken (2016) para delimitar categoricamente toda a produção artística que se encontra abrigada institucionalmente e que, portanto, de acordo com seu argumento, goza de visibilidade e de legitimidade no circuito artístico ${ }^{4}$. Para elaboração da análise apresentada no artigo, considerei que o processo de inserção de exposições de linguagens híbridas na programação de equipamentos culturais acontece em relação a diferentes segmentos do mercado de arte contemporânea, não exclusivamente em relação ao campo de produção rotulado comumente como "arte contemporânea". De acordo com Raymonde Moulin (2007), o mercado de arte contemporânea é segmentado em duas esferas heterogêneas. A primeira poderia ser classificada como arte acadêmica, que se volta para a figuração tradicional. As galerias consagradas por este mercado procuram excluir o risco associado à inovação, trabalhando sobre critérios e convenções de produção em função de expectativas estabelecidas de apreciação.

\footnotetext{
2 O emprego do termo "equipamento cultural" se dá deliberadamente por sua nomenclatura abrangente. A um só tempo, o termo contempla instituições, espaços ou edificações que se propõem a organizar práticas culturais a partir de uma programação, assim como também contempla produtores culturais que, associados coletivamente para realização de determinado prática cultural, são abrigados por alguma organização ou entidade interessada no fomento à cultura (ver TEIXEIRA COELHO, 1997).

${ }^{3}$ Com o termo, indico a definição de Lúcia Santaella (apud ARANTES, 2005, p. 49), que compreende a hibridação como processos onde diferentes sistemas de signos se atravessam e se contaminam em torno da formação de uma nova sintaxe integrada.

${ }^{4}$ Não raro o autor confunde o termo com a ideia de arte contemporânea, uma vez que procura politicamente contrapor as dificuldades encontradas pela new media art para que consiga efetivamente participar de uma história da arte contemporânea. Ao opor arte mainstream da new media art no circuito de arte, são enfatizados os entraves técnicos e discursivos para exposição das linguagens híbridas em veículos considerados mais convencionais.
} 
O segundo segmento está mais associado ao rótulo de "arte contemporânea". Costuma se designar à tradição moderna de ruptura e às criações de desconstrução narrativa pertinentes ao pluralismo cultural, que desmantelam a ideia de uma homogênea (e hegemônica) história da arte. A produção de valor neste circuito é fortemente pautada na formulação de discursos em torno da obra, organizada de forma expressiva por um grupo de intermediários composto por curadoras, marchands e pesquisadores.

As artes participativas 5 , compreendendo também neste contexto as linguagens híbridas interdisciplinares, se apresentariam como uma forma de criação de comunidades, em que o público poderia se identificar mais com o equipamento cultural como lugar de encontro e de entendimento. Esta abertura se dá pela compreensão de que as linguagens híbridas proporcionariam ao público um ambiente lúdico e afetivo de interação com a obra de arte, encontrando na jogabilidade sua materialidade estética (ver BOISSIER, 2004). A jogabilidade tem sido defendida recentemente como uma das características mais pertinentes da produção artística em linguagens híbridas. Esta qualidade é constituída através da possibilidade de exploração semântica da imagem em que o espectador, a partir de investimentos do corpo sobre a proposta, descobre através da reação da instalação outros desdobramentos visuais. Com o convite para "habitar" a imagem, o público pode atravessar os limites da perspectiva e do enquadramento, se apropriando e percorrendo os meandros da tridimensionalidade do regime de visualidade sempre em diálogo com a maquinaria engendrada. Portanto, o constante feedbacke adaptabilidade da interação com a instalação são fatores importantes (ver MANOVICH, 2001).

Cada vez mais o espaço cultural procura formas de compartilhamento do tempo - em que o artista desenvolve projetos junto ao seu público, investigando os ritmos que movem e mobilizam o espectador. Com isso, o significado da experiência com a obra de arte está cada vez mais conectado com as condições e modulações do momento de contato do espectador com a proposta artística. São as possibilidades de relação que constituem a forma, ou a materialidade, da obra de arte (BOISSIER, 2004). Segundo Martha Buskirk (2003), a emergência de

\footnotetext{
${ }^{5}$ O termo artes participativas é utilizado pelo curador Rudolf Frieling (2016) para descrever toda proposição artística promovida ao longo do século XX e XXI onde o artista procura ativamente desestruturar posições convencionadas entre espectador, objeto de arte e artista que então determinava um movimento semântico encerrado e fixado previamente pelo próprio artista antes de ser exposto.
} 
linguagens artísticas que se apropriam de inusitados suportes e técnicas, que deslocam materiais de suas funções convencionais, a fim de estimular novas sensibilidades em contato dinâmico com o espectador, tem alocado preponderante relevância aos meios de contextualização do público imerso na situação de visitação.

A mudança sobre a forma como a própria instituição ${ }^{6}$ percebe como deveria estar se relacionando com seu público e arredores carrega consigo o questionamento sobre quais têm sido os alternativos modelos expográficos criados para dar conta deste novo relacionamento. Mais especificamente, a interrogação sobre como construir conhecimento sobre o público destas exposições, uma vez que centralizam sua disposição expográfica nas condições de acesso e de interação do espectador com a obra de arte - e não tanto nas condições do objeto. Ao longo deste artigo, me ocupo em verificar como abordar a experiência do público neste ascendente contexto de concepção curatorial, investigando particularmente como deve ser constituído o posicionamento do pesquisador em relação ao público na situação de exposição. A partir da análise sobre minha própria experiência ao pesquisar o público nas exposições Bienal de Arte Digital: Linguagens Híbridas e Disruptiva, exposição do Festival Internacional de Linguagem Eletrônica, ambos decorridos ao longo de 2018, pondero orientações metodológicas sobre como se aproximar do espectador durante este momento dinâmico de construção e de sentidos sobre a proposta artística. Através da avaliação sobre como diferentes agentes negociam ao longo da exposição novas concepções sobre o lugar do espectador, disserto como, enquanto pesquisadora, conseguia compartilhar processualmente o tempo com este público na formulação performática de sua disposição em torno da obra de arte para a escrita etnográfica.

A pertinência da reflexão sobre este posicionamento se apresentou por conta do instável entendimento no campo da arte sobre como o espectador deve apropriadamente receber as obras de arte que investigam inusitados suportes e técnicas. A entrada de projetos expográficos que relacionam arte, ciência e tecnologia em equipamentos culturais não implica na qualificação sobre de que maneira deve se dar a sua organização. Os meios pelos quais a participação e integração

\footnotetext{
${ }^{6}$ Por instituição cabe a compreensão de uma organização que detém determinada autoridade para regulamentar e reger convenções e modos de produção cultural. Essa regulação, nas instituições, é concretizada mediante a observação de códigos de conduta ou mesmo de normas jurídicas particulares ao campo (ver TEIXEIRA COELHO, 1997; WILLIAMS, 1992).
} 
do espectador devem ser estabelecidos na instituição ainda estão em extensa negociação. É necessário compreender como os diferentes entendimentos sobre a posição do espectador são disputados enquanto a cena de visitação se desenrola enquanto seu percurso pela exposição, assim como suas expectativas e impressões, estão em jogo. Durante o artigo, é enfatizado como o estudo sobre o recorte material da expografia contribui para uma análise crítica sobre as exposições de arte e tecnologia. Contudo, seu enfoque está na promoção de uma escrita etnográfica afetiva sobre o lugar do espectador como meio de adquirir novos dados para a reflexão sobre os modos de exibir linguagens híbridas.

\section{Modelos expográficos experimentais e a arte contemporânea}

A categoria arte contemporânea deve ser analisada não por conta de sua localização cronológica em relação a diferentes movimentos artísticos do passado, mas por conta de uma série de condições relacionadas a sua produção, fruição e posicionamento no circuito de arte. O termo não se refere necessariamente ao que se produz atualmente. De acordo com Nathalie Heinich (2014), a arte contemporânea pode ser entendida algo como um gênero; contudo, não deve ser delimitada como um movimento estético. Ela está mais próxima da ideia de gênero enquanto uma forma específica de articulação de atores dentro do campo da arte. A arte contemporânea compartilha com outros mercados artísticos o cenário do circuito de produção, distribuição e fruição, sendo que cada mercado está organizado de forma autônoma (ver MOULIN, 2007). Cada qual "joga" com seus limites e ordens, de modo que a arte contemporânea usualmente privilegia a jocosidade e $\mathrm{O}$ sarcasmo como qualidade para explorar junto ao público uma noção de arte que extrapola o senso de arte em si.

Não costuma demonstrar ter nenhum vínculo com a obra de arte e a interioridade sensível da expressão do artista. Não raro emprega a maestria das técnicas consolidadas para a produção artística como meio para desmantelar a experiência em torno da obra de arte, extrapolando regras de comportamento e normas de conduta estabelecidas em museus, assim como de restrições e medidas sobre como produzir, transportar e preservar. O investimento dos agentes do meio não é mais realizado tanto sobre o objeto, pois ele não constitui mais, em si mesmo, a integridade da qualidade linguística. A materialidade técnica 
estruturante do objeto de arte não está em maior evidência do que as narrativas que são elaboradas em torno do objeto, das ações e reações que este objeto provocou. Esta característica proeminente não quer dizer que necessariamente o público em geral se sente mais "próximo" às propostas de arte contemporânea; ao contrário, a renovação constante de parâmetros pode deixar os visitantes confusos e perdidos de forma a não se sentirem convidados a compartilhar da experiência.

Claire Bishop (2013) assinala como a emergência de novos modelos expográficos tem requalificado a noção sobre o que é a arte contemporânea e como essa revisão se situa no enfoque estratégico sobre a experiência de visitação. De acordo com a pesquisadora, esta mudança está relacionada fundamentalmente ao processo de descentralização da história da arte. Sua narrativa histórica não tem sido mais compreendida a partir de uma visão positivista e de uma perspectiva linear, contemplando apenas 0 desenvolvimento de práticas artísticas ocidentais e europeias. Ao contrário, cada vez mais se buscam novas formas de dar conta de alternativos e "estrangeiros" modos de fazer artístico e de distintas referências culturais através de gestões museológicas mais laboratoriais.

A partir de uma análise crítica, a historiadora (ibidem) observa que a tendência por uma diversificação programática do museu, expandindo sua atuação para disciplinas pouco vinculadas ao campo da arte (como a ciência e a tecnologia), procura envolver o espectador a partir de uma alternativa postura e posição sobre $a$ arte e a instituição. A aquisição e manutenção de vasto acervo deixam de ser o seu principal foco para enfatizar projetos expográficos que estimulem novos modos de participação e de representação política.

Nathalie Heinich (2007) também identifica o maior número de projetos expográficos de caráter temporário em contraponto às exibições permanentes de acervo. Devido a essa característica emergente, a aquisição e conservação de acervo deixaram de configurar a principal função dos espaços expositivos priorizando, com isso, a possibilidade de circulação das obras entre instituições. Portanto, a possibilidade de criação de projetos que visem 0 intercâmbio e a troca. A partir desse novo cenário que se consolida, é cada vez mais valorizada a diversidade programática da instituição, que passa a receber uma maior variedade de temáticas nas exibições. A socióloga (ibidem) observa como os espaços expositivos começam a receber maior 
número de disciplinas e interesses expográficos fora da produção convencionalmente atribuída ao campo da arte, diversificando os mecanismos e métodos de exposição de acordo com a qualidade ou natureza do assunto.

Portanto, a consciência construída de que o equipamento cultural seria capaz de contextualizar expograficamente situações que formalizem novos modelos de relação entre o sujeito e o objeto através do inusitado display de linguagens híbridas tem mudado as características estruturantes dos modos de exibir. Esta mudança da função do espaço expositivo está fundamentada crucialmente no enfoque atribuído à participação do público ao visitar a exposição. Contudo, se o rigor técnico e as rígidas posturas e referências estéticas para a produção artística foram gradativamente desconstruídas com 0 uso interdisciplinar de objetos, materiais e suportes para alternativos modos de participação do espectador (CORNWELL, 1992), os meios de assimilação e de cooptação de tais iniciativas nos espaços expositivos ainda têm sido minuciosamente estudados e disputados dentro do campo (FRIELING, 2016). Com isso, a proposta de repensar metodologicamente como se aproximar da experiência do público se torna fundamental para compreender quais são as negociações empreendidas sobre o lugar do espectador neste emergente contexto de reformulação da gestão museológica.

De acordo com o diagnóstico de Rudolph Frieling (ibidem), esses trabalhos mais colaborativos realizam acontecimentos, performances ou instalações a partir da articulação de ficções condicionadas artificialmente dentro de uma temporalidade própria. As instituições expositivas têm a tendência em engendrar a experiência de participação colaborativa através da exibição de registros, documentos e relatos sobre a performance, sem realmente assumir 0 desafio de dar continuidade a esta temporalidade narrativa vivenciada. Portanto, encontra grande dificuldade em recontextualizar trabalhos artísticos que enfatizam a experiência processual e que, usualmente, investigam questões como a precariedade ou a vulnerabilidade das condições de existência do corpo, a efemeridade e a espontaneidade das relações, além da imaterialidade dos suportes.

Richard Rinehart (2016) ressalta que estes impasses institucionais estão intimamente atrelados a sua gestão centralizada no objeto de arte em si. Portanto, o museu ainda se estrutura em torno da ideia de que a preservação da obra de arte só pode se dar 
mediante os cuidados sobre suas condições materiais e físicas. Por enfatizar este modo de conservação, a instituição (sempre) parece carecer de meios técnicos para atender as demandas dos trabalhos. Seja porque o soffware desenvolvido depende de conhecimento qualificado de ponta, de modo que poucos profissionais compreendem com maestria sobre a tecnologia. Seja porque o aparato técnico utilizado está obsoleto do ponto de vista industrial e comercial, de modo que muitas peças integrantes do aparelho não são mais produzidas.

Como salienta Giselle Beiguelman (2004), a qualificação da organização dos desenhos das exposições de arte e tecnologia nos espaços culturais somente será possível quando for dada abertura para atendimento das demandas de suas propostas que não são definidas por demandas técnicas. Apesar do interesse demonstrado pelas linguagens híbridas, a ausência de reflexão sobre o que é, de fato, explorado por suas propostas e, portanto, sobre o que deve transparecer expograficamente evidencia $O$ profundo isolamento das linguagens híbridas em relação à arte contemporânea. A pesquisadora (ibidem) descreve como as exposições produzidas recentemente parecem não poder ser "confrontadas" com outras formas de expressão e outras linguagens - sua particularidade está sempre encarcerada pela questão do uso de inovações tecnológicas, como se a sua experimentação se encerrasse neste tópico.

Sarah Cook (2008) destaca que a dificuldade em dispor tais trabalhos se dá porque o conhecimento sobre a situação de exposição usualmente está estruturado a partir de uma noção de comportamento estático e homogêneo do espectador, que gerenciaria o seu tempo da mesma maneira pelo espaço. Com isso, compreende que as obras de arte agenciam os mesmos modos de recepção - o que não é o caso quando se trata de linguagens híbridas. As relações entre arte, ciência e tecnologia são dinâmicas e mesmo instáveis, onde cada proposta investiga novas temporalidades. Ao mesmo tempo em que a curadoria precisa estabelecer um ambiente seguro para a preservação da proposta por bastante tempo no espaço expositivo, ela também precisa ser flexível e cooptar as distintas disposições do espectador, que variam consideravelmente com sua bagagem cultural, assim como com suas condições de visitação.

Entretanto, não são apenas os espaços expositivos que projetam barreiras para assimilação destas propostas, continua a autora (ibidem). As experimentações artísticas relacionando ciência e 
tecnologia criaram um circuito de circulação próprio, possível através da criação de plataformas e de redes de relacionamento virtuais exclusivas. A curadoria de tais projetos se baseia na mobilização de um conjunto específico de pessoas pertencentes a uma mesma comunidade online a fim da realização colaborativa de uma ação de curta duração. Neste caso, não há uma distinção objetiva entre organizadores, colaboradores, público e artistas, pois a presença no evento se dá mediante apresentação do que a pessoa pode contribuir para a realização da atividade em questão.

Ao longo do desenvolvimento da atividade, transmissão e produção são simultâneas e interdependentes - a experiência artística reside neste incessante e instantâneo feedback. Com isso, as pessoas envolvidas no segmento se acostumaram a contar com a formação prévia de uma comunidade iniciada - ou seja, um público interessado e especializado. Por mais que possa ser gratificante ao artista reunir para si apenas pessoas que estejam, de fato, alinhadas ao seu pensamento, trajetória e experimentação, este comportamento expográfico tende a compartimentalizar muito o acesso a estes trabalhos. Desse modo, existe uma dificuldade em estabelecer a qualidade de tais experiências para um público mais amplo, que não necessariamente compartilha dos mesmos valores e códigos. A fim de preparar a pesquisa em torno da realização de tais exposições, compreendendo como avaliar sua receptividade, considerei necessário atentar para dois recortes fundamentais que atuam complementarmente na configuração da curadoria: o recorte sobre a expografia e o recorte sobre a visitação.

\section{Recorte sobre a expografia}

Para preparar a entrada em campo, é preciso discriminar de antemão quais fatores em negociação no ambiente expositivo estão materializados pela disposição das propostas artísticas. No primeiro módulo deste artigo, procurei enfatizar quais os principais fatores formuladores das disputas no contexto de exposição das linguagens híbridas. Para planejamento do modo de inserção em campo, entendi a necessidade em compreender as traduções empreendidas na expografia: as possibilidades de transmissão de determinados conceitos pertinentes à obra de arte considerando as possibilidades infraestruturais da instituição expositiva. 0 processo de tradução não implica na produção de um objeto ou de uma instalação que possa simplesmente ocupar "fisicamente" 
o espaço expositivo: significa criar meios de contato com um público visitante que não necessariamente conhece previamente os conceitos agenciados pelo artista através da tecnologia (QUARANTA, 2010).

Para cuidar da análise do cenário que forja a mediação do público com a coleção em exposição, é necessário considerar as conformações resultantes dos cruzamentos entre as delimitações arquitetônicas e infraestruturais do espaço expositivo com as concepções expográficas propostas pela curadoria. Ao tratar destas articulações, não observo apenas o plano de disposição das obras de arte pelo espaço, mas também estou considerando os veículos intertextuais de comunicação com o público - como a existência de textos introdutórios apresentando a exposição; a localização de bilheterias; as formas de entrada para as galerias da exposição; a disponibilidade de programas ou mapas da exposição, e etc.

Ao longo do percurso do visitante pela exposição, são constatados diversos mecanismos (visuais, espaciais, físicos, sensoriais) a fim de proporcionar uma experiência compartilhada de códigos, referências e valores. $O$ empreendimento para compartilhamento da experiência sempre se trata, sobretudo, do compartilhamento de uma ideia de experiência. Os pontos de comunicação não se dão senão mediante uma série de ruídos. Mesmo considerando uma proximidade entre os diferentes atores envolvidos na situação de exposição, o compartilhamento dos mesmos cenários culturais e sociais não reassegura a possibilidade de entendimento dos mecanismos de comunicação que visam articular possíveis disposições materiais para apreciação da exposição (VELHO, 1997). Então, para observar os veículos intertextuais de comunicação, é necessário realizar uma comparação entre as intenções e iniciativas de comunicação engajadas tanto pela organização do projeto quanto pela instituição e os usos e apropriações que os espectadores realizavam.

Por exemplo, durante a exposição Disruptiva procurei observar se as regras para retirada do ingresso do centro cultural manifestavam alguma forma de conduta do público. Algumas instalações componentes da expografia demandavam pausas para manutenção do aparelho. Outras requeriam que apenas determinado número de pessoas manuseasse sua interface antes do sistema se encontrar saturado e precisar de resfriamento. Para tanto, a mediação se encontrava responsável pela distribuição de 
senhas e organização de uma fila de entrada. Esta configuração poderia interferir em como o público organizava seu fluxo de visitação, uma vez que, por determinado período, estas obras se encontrariam indisponíveis.

No caso da Bienal de Arte Digital, ao observar a estrutura de ligação e passagem entre as galerias do centro cultural, a comissão organizadora decidiu disponibilizar totens de comunicação para instruir ao público de que a exposição poderia seguir por determinado caminho. O espaço cultural era absolutamente silencioso. A curadoria apresentou etiquetas junto às obras de arte que não apenas descreviam seu título e ano de criação, mas também um texto produzido pelo próprio artista. Para mim era interessante observar como estas propostas seriam assimiladas pelo público visitante, se orientariam seu percurso através destes totens, se tomariam tempo para considerar o texto da etiqueta, e como essas interações materiais modulavam a forma como o espectador acompanhava a exposição.

Como sinaliza o historiador Brian O'Doherty (2002), o formato do espaço expositivo é resultado do compartilhamento de determinadas convenções sobre como a obra de arte deve ser percebida. A arquitetura e a infraestrutura da galeria materializam uma historia de disposições disputadas, resultando em determinados condicionamentos materiais para que o espectador aprecie como esperado. A galeria ratifica modulações e compressões sobre o seu corpo para que sua presença seja adequada à preservação e à contemplação da obra de arte. Segundo o autor, é preciso atentar aos distintos mecanismos físicos que são empregados pela instituição a fim de que o visitante se sinta compelido a se comportar de forma diferenciada, demonstrando zelo pelo objeto valioso disposto. Portanto, aspectos como a temperatura e a iluminação do local podem ser relevantes na constituição da experiência de recepção. O espaço expositivo veicula em seu próprio design como acessar o conhecimento destacado através da obra de arte, e que vontades devem ser subtraídas a fim de participar desta experiência de conhecimento. Uma vez que as exposições de arte e tecnologia agenciam alternativas posturas para uma participação mais engajada e lúdica do público, não raro são encontrados choques de concepção do espaço para as propostas em exposição. Contudo, o planejamento do pesquisador em torno de sua pesquisa de campo em exposições de arte e tecnologia não podem se delimitar às considerações das conformações materiais da expografia. 


\section{Recorte sobre a visitação}

Uma modulação expressiva da experiência do público ao visitar exposições de arte e tecnologia acontece nos modos de atendimento e relacionamento promovidos tanto pela organização do projeto quanto pela instituição expositiva. Não obstante, as relações interpessoais entre os visitantes proporcionadas pela prática de visitação demarcam também meios de acesso ao conhecimento exposto pela situação de exposição. Os contatos promovidos entre diferentes atores envolvidos condicionam tempos e disponibilidades do espectador. De acordo com o diagnóstico de Hooper-Greenhill (1988), a avaliação sobre o "sucesso" de uma exposição não deve deixar de passar pela observação da relação entre o planejamento e gestão de estratégias de comunicação com o público-alvo visado pela produção e as interações e vivências do público visitante com estes recursos mediadores.

Para mapear esses pontos de contato e de mediação, devem ser pesquisados, primeiramente, como são formulados os planos educativos, assim como as suas formas de implementação, em relação com a mediação visada. No contexto de trabalho de campo, deve ser observado como se dava a relação entre a visão da instituição sobre a abordagem educativa e os objetivos de comunicação da organização da exposição. Durante a minha pesquisa, foi pertinente verificar quais eram as percepções e noções norteadoras para elaboração de cada abordagem e atendimento ao público através de entrevistas com os coordenadores educativos de cada domínio. Além disso, também acompanhar o treinamento e a formação dos profissionais que executariam cada planejamento. Neste momento, considerei preciso compreender como as noções sobre atendimento educativo conformavam ideias sobre o que seria a experiência de público apropriada para esses agentes e profissionais (MUNIAGURRIA, 2006) e então, consequentemente, como poderiam estimular determinadas interações, ações e fluxos.

Retomando o ponto sobre a necessária pausa para manutenção dos aparelhos de determinadas instalações em Disruptiva, procurei anotar como os organizadores do projeto orientavam a conduta dos monitores a respeito do público ansioso por informações sobre quando a obra retomaria as atividades e como, ao longo da exposição, os monitores adaptariam essas diretrizes para respostas que considerassem mais eficientes. Da mesma forma, como o 
departamento educativo assimilaria esta condição temporal de funcionamento dos trabalhos. Em relação à Bienal de Arte Digital, procurei identificar se os visitantes buscavam retorno sobre os significados de determinada proposta artística com outros visitantes, funcionários de segurança e equipe administrativa, uma vez que o projeto não contou com monitores para orientação do público. Concomitantemente, se esta ausência interferia na forma como distribuía seu tempo pelas obras dispostas pela galeria e seu interesse por determinado trabalho - os visitantes poderiam acabar investindo maior atenção aos trabalhos de grande porte e mais complexos em termos de montagem técnica, por exemplo.

A partir da análise sobre as políticas de atendimento e abordagem ao público, se tornou evidente que era preciso o estudo sobre os diferentes espectadores da visitação espontânea. Não seria possível compreender as interações do público através de uma mera dualidade entre público espontâneo e público agendado. Primeiro porque não necessariamente os dois tipos de visitação são distintos - seria preciso verificar esta pressuposta discrepância. Segundo, o público espontâneo, assim como os diversos grupos agendados para atendimento educativo, não se configura como uma entidade homogênea, que acessa a exposição a partir das mesmas condições e circunstâncias de visitação. A prática de visitação foge do senso comumente conduzido de que a interação do público com a obra de arte é fundamentalmente uma prática individual e solitária - e mais, uma prática desinteressada.

Ao compreender a visitação a uma exposição de artes plásticas enquanto uma prática social (DABUL, 2005), é assinalada a importância em observar as interações e relações estabelecidas entre diversos atores ao longo da prática de visitação. Lígia Dabul (2008), a partir de sua pesquisa, conclui que o público ao visitar uma exposição de artes plásticas realiza, conjuntamente, diversas atividades pertinentes ao uso do tempo livre, como conversar, brincar, namorar, estudar, fotografar. Todas estas atividades acontecem ao longo do percurso do visitante pela exposição (elas não acontecem distanciadas da interação com a obra de arte), de modo que modulam a própria experiência de recepção.

Enquanto entram em contato com as obras de arte, os visitantes procuram o feedback do outro, interagem entre si, acionam afetivamente relações com os outros agentes envolvidos independente de ser um público espontâneo ou agendado. Toda esta composição de comportamentos, segundo a autora (ibidem), 
encontra as seguintes variáveis: se a galeria está cheia ou vazia; se está barulhenta ou silenciosa; se o espectador está acompanhado de grande número de pessoas, ou se está em dupla, ou se sozinho; se está com amigos, familiares, cônjuges, colegas de trabalho; se o grupo de visitantes que lhe acompanha é composto por crianças ou por idosos; de quanto tempo o espectador dispõe para a atividade; e como se relaciona com os diferentes departamentos de atendimento. Com isso, a produção de sentidos engajada pela troca entre público e obra de arte, assim como a "lisibilidade"7 dos conceitos articulados materialmente pelo artista e pela curadoria, depende também dessas interações sociais forjadas coletivamente entre os visitantes, assim como entre os visitantes e demais atores envolvidos.

Por conta de sua avaliação, indico algumas categorias de análise pertinentes para planejamento da pesquisa sobre a experiência de público, distinguindo diferentes tipos de público e de visitação para além da polarização entre espontâneo e agendado - mas sem deixar de reconhecer complementarmente esta diferença. É preciso, antes de tudo, compreender quando o espaço expositivo costumava receber maior e menor fluxo de visitantes. A partir desta primeira observação, disposta após frequência assídua à exposição, separar quando a instituição recebia mais visitantes em contexto profissional; em contexto pessoal, em uma visitação solitária ou em companhia; e em contexto educativo (quando recebia grupos agendados para mediação educativa). Esta distinção pode ser realizada através da separação de turnos da manhã, da tarde e da noite, destacando horário de almoço e horário de saída (do trabalho e da escola). Também é relevante realizar uma diferenciação dentro dos dias da semana. Com isso, no início do trabalho de campo, é necessário identificar quais tipos de visita o espaço recebia - nem sempre todas estas categorias de análise realmente frequentavam a exposição estudada ${ }^{8}$. Durante minha experiência, constatei que cada exposição apresentava discrepantes fluxos de visitação em estreita relação com a forma com que o equipamento cultural se inseria no seu entorno. No caso de Disruptiva, por estar situada em um centro cultural no centro da cidade, em uma rua de trânsito e

\footnotetext{
${ }^{7}$ O termo utilizado pela autora (ibidem) parece se referir a habilidade ou capacidade adquirida de se tornar perceptível ou legível em termos de signos e significados.

${ }^{8}$ A diferenciação entre grupos de visitantes em contexto pessoal e em contexto profissional se deve porque, apesar de realizarem a prática de visitação para estreitamento de vínculos formados previamente, a postura observada era diferente. A interpretação obtida mediante a observação era de que, em contexto profissional, o visitante procura constituir determinada imagem de si mesmo, enquanto que, em contexto pessoal, procura se relacionar com os entes queridos a partir de outra percepção sobre si mesmo.
} 
movimentação de trabalhadores e estudantes, com uma programação concomitante bastante diversificada, percebia diferentes tipos de grupo de visitação, cuja intensidade variava com a hora do dia. No caso da Bienal de Arte Digital, por ser um espaço cultural em um bairro residencial, seu maior fluxo de visitantes se dava em um horário bem marcado e específico.

Não obstante, para articular o meu posicionamento como pesquisadora em campo, foi preciso reconhecer, de antemão, que cada tipo de visita é atravessado por distintos interesses e expectativas sobre a própria situação de exposição. Segundo Hooper-Greenhill (1988) ${ }^{9}$, ao longo do trabalho de campo, é necessário ter em mente que o público pode demonstrar os seguintes objetivos com sua frequência a museus e outros espaços expositivos: a) estar junto de outras pessoas; b) fazer algo enriquecedor com seu tempo livre; c) utilizar um local conveniente e agradável como ponto de encontro; d) ter experiências desafiadoras; e) ter uma oportunidade de conhecer ou de aprender algo novo; f) realizar uma atividade mais participativa ou engajadora em seu tempo livre. Procurei identificar quais grupos frequentavam as diferentes exposições e, ao mapear as distintas motivações para visitação aliadas às circunstâncias para realização da mesma, como orientavam a forma como orientavam seu percurso pela exposição.

A partir desta constatação, para poder perceber as nuances das disposições do público ao visitar a exposição, percebi ser necessário formular uma abordagem que não desse muito espaço para que o público mudasse de comportamento e postura ao constatarem minha posição como pesquisadora. Com isso, os modos e circunstâncias pelas quais realizaria a minha inserção em campo seriam determinantes para a constituição da análise. Na escrita etnográfica, a realidade retratada nada mais é que a interpretação das circunstâncias de trabalho de campo que são delimitadas através de negociações agenciadas entre pesquisador e os atores envolvidos na prática cultural (CLIFFORD, 2002).

\section{Como abordar o público: o público, antes de tudo, sou eu mesma}

\footnotetext{
9 Em seu argumento, a autora cita como principais referências analíticas ambas pesquisas de Marilyn Hood sobre o tema: Staying away - why people choose not to visit museums. Museum News, n.61, v.4, 1983, e sua tese de doutorado, Adult attitudes toward leisure choices in relation to museum participation. Columbus, EUA: Ohio State University, 1981.
} 
Ao longo do relato de Lígia Dabul (2005), era observado como os agentes do centro cultural pesquisado se relacionaram de forma diferenciada com ela uma vez revelada a sua posição como pesquisadora. A socióloga descreve como estes atores procuraram se aproximar para detalhar suas próprias impressões e entendimentos sobre as obras de arte expostas, demonstrando certo orgulho quando ela expressava interesse em anotar os seus comentários. Em relação ao público, sua solução foi se posicionar como uma dos agentes do centro cultural, reservada em alguma localização que os seguranças adotam normalmente para obter uma visão mais ou menos privilegiada da galeria e de seu fluxo. A pesquisadora poderia, com alguma desatenção, ser confundida com alguns dos funcionários do espaço e assumir uma posição de observação mais naturalmente convencionada. Como eu tinha a intenção de também observar as formas de relacionamento e de mediação dos funcionários com os espectadores em diferentes cenários de visitação, logo descartei a possibilidade de estar "mais próxima" de um lado do que de outro na entrada em campo. A princípio, resguardando o inevitável momento em que os agentes mediadores se familiarizariam com a minha presença, também tinha a intenção de entender como agiriam sem a sensação de que estavam sendo observados.

Portanto, para abordar a experiência do público de forma mais sensível, eu teria de assumir uma aproximação mais subjetiva e afetiva: ou seja, eu teria de ser, antes de tudo, o público tão logo a exposição estivesse em cartaz. Não obstante, a opção por este posicionamento para a escrita etnográfica precisa considerar e cuidar de algumas problemáticas. A manutenção de um distanciamento do observador em relação ao objeto de estudo é um aspecto metodológico tradicional que tem sido amplamente revisado na disciplina da etnografia há algumas décadas (ver CARDOSO (org.), 1996), especialmente no contexto de emergência de uma nova metodologia para a etnografia urbana que despontou no cenário brasileiro a partir de 1970 (ver MAGNANI, 2002).

Contudo, como observa Gilberto Velho (1978), apesar da demanda em procurar "se colocar no lugar do outro", pouco se compreende como deve ser empreendido este esforço. A aproximação como método pode também se apresentar como uma ilusão, e contaminar a coleta de informações e análise dos dados de outra forma. O autor avalia como este empreendimento também encontra outras distâncias em seu caminho, pois é preciso considerar analiticamente a distância social e a distância 
psicológica enfrentada inevitavelmente pelo pesquisador. Para a criação de formas efetivas de envolvimento e participação, é preciso forjar pontos de entendimento entre o pesquisador e o objeto de estudo que por vezes está além da comunicação verbal.

Por ser uma pessoa que também tem em sua trajetória profissional a atuação como produtora cultural, a situação de exposição e sua dinâmica correspondente me eram intimamente familiares. Esta premissa pôde me servir de forma muito benéfica para formular e conduzir as entrevistas com os profissionais relacionados ao processo de montagem da exposição, por ter uma ideia prévia de quais poderiam ser os problemas técnicos e administrativos que uma produção encontraria dadas as demandas dos trabalhos de arte e tecnologia. Acredito que eu tenha desenvolvido um olhar sobre quais detalhes da montagem eu poderia direcionar minha atenção, conhecendo que modos eram diferentes de outras exposições de arte. Da mesma forma, a experiência profissional prévia no ramo me auxiliaria no acompanhamento da abordagem educativa, pois havia atuado extensamente no setor em outros centros culturais e, então, partilhava da formação sobre alguns preceitos e valores constituintes do plano de mediação.

Por exemplo, eu antecipei muitas interações anotadas em meu diário de campo por conta de minha trajetória profissional, antevendo algumas atividades que tradicionalmente $\mathrm{O}$ setor educativo gosta de engajar, como utilizam certas perguntas para estimular o pensamento crítico no espectador, para fazer com que fale e se expresse mais. Além disso, por estar acostumada que o público não "goste" de ler as etiquetas, eu logo me posicionei, nos primeiros dias da pesquisa de campo, para contemplar se, nos casos particulares destas exposições, quais dinâmicas e relações se davam em torno deste recurso intertextual tão sensível.

É preciso, entretanto, estar assombrada pelas distâncias existentes que eu poderia não estar ciente previamente por estar "de perto". Como enfatiza Roberto Da Matta (1978), o que sempre vemos e presenciamos pode nos ser familiar, mas não necessariamente nos é conhecido. Eu poderia compreender como se dava a distribuição de códigos, tradições e valores que sistematizam a produção de exposições de artes plásticas. Eu poderia dispor das normas e condutas que estruturam cenários de interação e as condições vigentes para o compartilhamento de experiências. Contudo, eu sempre tomei uma posição nestas 
interações e relações por ser uma produtora. Até o desafio do trabalho de campo e da escrita etnográfica, sempre assumi uma postura de acordo com a minha visão sobre como as interações deveriam se dar. Também disputava sobre o que considerava ser adequado. Esta postura poderia intervir nos meios de observação caso não tivesse a consciência e cuidado de trabalhar sobre isso. Por exemplo, costumeiramente eu entendo que a curadoria sempre planeja sua estratégia de comunicação visando a um espectador mais especializado, negligenciando alguns aspectos da disposição das obras de arte por não ter se preocupado em se colocar no lugar de um outro que nunca ouviu falar de arte contemporânea nem de história da arte. Esta postura foi severamente analisada e revisada ao longo da pesquisa de campo, principalmente no contato com os profissionais organizadores das exposições, para que eu entendesse empaticamente suas perspectivas sobre como deveria se dar a interação do público com as linguagens híbridas, disposição esta em extensa disputa e negociação, como foi articulado nas seções primeiras do artigo.

Como alerta Velho (1978), por ser uma realidade familiar, o pesquisador tem a capacidade de reconhecer, de forma um tanto grosseira, as hierarquias de valores e discursos que articulam diferenças entre os atores envolvidos no mesmo cenário e prática social. Sem questionar a sua própria posição nesta hierarquia, entretanto, o pesquisador apenas vê como os diferentes atores acessam de formas distintas a mesma prática. Não consegue, assim, relacionar criticamente como estes distintos acessos constituem experiências e significados diferentes, nem consegue em sua pesquisa analisar as distintas lógicas que mobilizam suas ações e posturas. Apesar disso, foi através desta familiaridade sobre posições e lugares esperados para a realização desta prática cultural que pude, particularmente, ao longo da observação participante, flutuar e oscilar entre papeis sem realmente ser notada.

Como situa Becker (1977), não é mais uma questão a observação absolutamente imparcial - já está esclarecida a impossibilidade desta abordagem objetiva. Inevitavelmente o pesquisador irá ter alguma forma de envolvimento e de posicionamento em relação ao objeto de estudo. Portanto, a problemática central na escrita e análise etnográfica está na forma como o pesquisador irá construir e tomar este posicionamento. É fundamental, antes de tudo, o reconhecimento de sua posição nas interações e relações construídas ao longo do trabalho de campo sobre a prática 
cultural estudada com os atores envolvidos. Com isso, continua o autor, é preciso reconhecer na escrita etnográfica a ordem estabelecida que organiza discursos e autoridades, ao mesmo tempo em que desconstrói a credibilidade desta distribuição para evidenciar a diversidade de modos de acesso ao conhecimento.

Por exemplo, em uma das exposições o contato com os organizadores se deu de forma muito concisa e seca nas primeiras mensagens, o que me surpreendeu bastante a princípio. Questionavam constantemente minhas credenciais, retornavam a perguntar sobre os objetivos da minha pesquisa e meu vínculo institucional sempre que achava que finalmente estava conquistando sua confiança. Sempre sem hesitar ou demonstrar desconforto, respondia o mais descritivamente possível como iria intervir na rotina de montagem da exposição, como abordaria os profissionais envolvidos e porque precisava analisar estes detalhes da exposição. Mesmo assim, eram muito solícitos, liberando o meu acesso. Não tardou muito para que, já no primeiro dia em campo, um dos coordenadores do projeto fizesse uma entrevista inquisitiva comigo. Acontece que os profissionais envolvidos tinham muito receio sobre minha posição como "pesquisadora", e se eu não estaria, na verdade, sondando dados e detalhes sobre a organização para fornecê-las a outros curadores. Se não fosse minha abertura, provavelmente não teria descoberto essa informação. Por outro lado, a outra exposição se mostrava estar muito envolvida com $\circ$ ambiente universitário, ansiando pelas entrevistas, disponibilizando de imediato as plantas da montagem, antecipando minhas questões e interessados em compreender as referências metodológicas que me levaram a abordagem apresentada no primeiro contato. Mais adiante, entenderia que esta disposição em relação a minha figura enquanto pesquisadora se relacionaria diretamente a forma como concebiam a expografia, assim como a forma como tais organizações se inseriam no campo de fomento e promoção das linguagens híbridas nos equipamentos culturais.

Para o desenvolvimento de minha pesquisa de campo a uma exposição de arte e tecnologia, compreendi que, por um lado, precisei questionar minha própria posição, visão e valores sobre o meio como uma delimitação condicionante do acesso aos dados e informações coletadas em campo. Era necessário, portanto, revisar as formas como o meu relacionamento estava sendo dado a cada nova etapa da pesquisa, analisando como as interações com os produtores, curadores, educadores, administradores e monitores poderiam estar sendo enviesadas de acordo com a 
perspectiva deles sobre a minha posição, ao mesmo tempo produtora e pesquisadora, assim como a partir de minha opinião sobre a função deles na situação de exposição. Por outro lado, complementarmente, precisei evidenciar com alguma destreza a hierarquia das mediações dadas nas interações dos diferentes públicos com a disposição curatorial $e$ as estratégias de comunicação implementadas, assim como o discurso das autoridades a respeito dos condicionamentos e modulações estipulados na manutenção destes modos de exibir.

Para compreender analiticamente as disputas em torno do lugar do espectador, tanto pelo recorte do planejamento expográfico e da curadoria, quanto das interações e contatos das diferentes práticas de visitação à exposição, se reafirmou a necessidade de me deixar "afetar" pelas vivências do espectador em sua visita e de transitar como uma visitante pela exposição pesquisada. A interpretação sobre as traduções empreendidas ao longo da exposição só poderia ser formulada quando pudesse suspender as condutas que normalmente desempenho como produtora enquanto realizava a pesquisa de campo. Favret-Saada (2005) enfatiza como $\circ$ relato de campo e a decorrente análise etnográfica precisa ressaltar o campo dos afetos vividos pelo pesquisador. Esta iniciativa compreende na desconstrução do papel da observação participante na coleta de dados.

A autora aponta que durante a observação participante, o pesquisador assumiria uma visão precária do que seria a sua "participação" na prática cultural estudada uma vez que sua participação normalmente se restringiria a sua presença durante a realização do evento, a um estar lá em testemunho. O pesquisador se basearia fundamentalmente na preservação de uma complexa rede de informantes "nativos" - que são os que, de fato, "participam" do evento. A antropóloga evidencia como a qualidade de sua observação e de sua inserção em campo se deve essencialmente ao momento em que os atores envolvidos na prática compreenderam que ela era como um deles, e havia sido "pega" pela feitiçaria. O acesso a uma diversidade de gestos, costumes, iniciativas e perspectivas dos atores se deu em um processo de envolvimento e participação que vai além da criação de "empatia" e de um vínculo com um informante.

Ao estar aberta a viver a experiência do público com o público, ou seja, ao abortar o distanciamento analítico sobre sua prática de visitação, é possível descrever com maior registro de impressões e vivências as modulações da recepção. Os visitantes 
transmitem sem maiores pudores suas expectativas e frustrações em relação à interação com as obras de arte dispostas. A partir de então se torna possível a realização de uma descrição densa (GEERTZ, 1989), em que não apenas relataria uma série de gestos, poses, ações, mas poderia compreender seus laços e conexões significativas. Através desta participação, é possível analisar com maior destreza o alcance e a repercussão de determinadas atitudes dos espectadores com outros agentes envolvidos na prática, e pude compreender quais mecanismos e lógicas impulsionaram suas disposições e posturas ${ }^{10}$.

Por exemplo, por ter reparado que os monitores eram preocupados, primordialmente, com a segurança do público e com a circulação dos visitantes, realizei alguns testes especificamente voltados para entender um pouco mais como estas preocupações conformariam a experiência de recepção. $O$ primeiro aspecto que queria verificar, muito por conta das dúvidas verbalizadas no período de treinamento da mediação, era a questão do tempo. Com isso, além de observar a interação entre visitante e monitor quando o visitante queria ficar mais tempo em contato com a obra, eu também forçava deliberadamente os seus limites.

Em pouco tempo compreendi que, mesmo sem entender exatamente como ou porque, os visitantes interagiam com a obra de arte pelo mesmo período de tempo - independente de qualquer incitação da mediação para esse gerenciamento. Do meu ponto de vista, este comportamento se dava pela mesma ordem que estimulava um visitante mais receoso a explorar um pouco mais as possibilidades da instalação ao observar que o visitante anterior era um pouco mais destemido: a compreensão de que vivenciava uma experiência coletiva. Mediante um acordo quase que inconsciente, a maior parte dos visitantes não se propunha a "demorar" demais na instalação, acompanhando a mesma gestão de tempo que os demais.

\footnotetext{
10 A partir desta imersão, pude constatar que os mediadores de uma das exposições assumiam muito mais do que a posição de auxílio técnico aos visitantes graças à integração em suas interações. Muitos visitantes não raro recorriam a esta figura a fim de solucionar uma série de questionamentos sobre a exposição, expondo assim extensa ansiedade sobre os possíveis significados da experiência de visitação. Ao mobilizar e instaurar uma sequência de cuidados e modos de usufruto em relação às obras de arte, os monitores eram vistos como uma entidade que distinguiria $\circ$ certo e o errado sobre a recepção. Enquanto aguardavam para entrar em determinada instalação, a maioria dos visitantes comentava entre si como achava que seria a experiência de contato com a obra - e a confirmação das especulações traçadas se dava pela autoridade do monitor. Sua imagem era acionada pelo público em diversos momentos da experiência, ávidos em saber: 1) o que esperar ao interagir com a obra de arte; 2) quanto tempo poderia usufruir da obra; 3) o que, exatamente, deveria fazer para acessar a obra.
}

CSOnline - Revista Eletrônica de Ciências Sociais, Juiz de Fora, n. 29 (2019) 
Neste contexto, percebia que o monitor agia quase que como no modo automático - não demonstrava grandes emoções. Contudo, alguns esparsos visitantes tentavam permanecer mais tempo imerso no ambiente da instalação - alguns pareciam estar certos de que fariam um book fotográfico com a experimentação; outros pareciam querer "provar" para seus companheiros que "conseguia" ficar mais tempo. Nestes casos, especialmente no Shrink 01995, os monitores começavam a demonstrar apreensão e ansiedade em torno do comportamento do visitante. Não raro eu via que eles começavam a sinalizar com os braços e as mãos na tentativa de indicar que o visitante deveria pedir para sair da instalação. Quando $O$ visitante demonstrava querer tirar fotos demais de sua experiência de interação, o monitor também tentava entrar em contato com o visitante através de gestos e caretas como um "tudo bem por aí", "tá tudo OK". Normalmente a pessoa percebia que era melhor se retirar.

Em outras ocasiões, eu demonstrava completa inabilidade em manusear ou em operar o equipamento, seja como posicionar os óculos de realidade virtual, seja como brincar com o joystick. Um dia cheguei a ir de óculos para a exposição, pois havia percebido que os monitores indicavam às pessoas que eles deveriam retirar seus óculos de grau para poder posicionar os óculos de realidade virtual. Claro que minha resposta foi não. Além de querer ver o que acontecia, eu realmente não consigo enxergar nem um palmo à frente sem meus óculos de grau. No primeiro dia, a monitora que havia me atendido ficou completamente desconcertada com minha resposta - perdemos um bom tempo com ela insistindo para que eu retirasse os óculos, enquanto eu prontamente sinalizava que não era possivel. Curiosamente, quando finalmente pude colocar os óculos de realidade virtual por cima dos meus, ela não me deixou interagir com a obra de arte por nem um minuto. Contudo, em outras ocasiões que realizei o mesmo teste, outros monitores não se importaram muito com esta sobreposição. Ao investigar estes limites, eu tentava ver quando o monitor sairia de sua postura convencionada com uma situação nova para então analisar se ele tentaria conformar a experiência para os moldes convencionais firmados. Minha conclusão sobre este aspecto do atendimento era de que variava consideravelmente com o próprio temperamento da pessoa, e também se alterava de acordo com o fluxo de visitantes. Evidentemente, quando estava bem cheio o centro cultural, os monitores ficavam um pouco mais tensos e atentos em manter determinado ritmo. 
Ao passo que as instituições culturais demonstram ascendente interesse em reformular suas estratégias e dinâmica de comunicação com o público, se apresenta em disputa diferentes perspectivas sobre como deve se dar esta integração. Os espaços culturais parecem estar mais dispostos a diversificar sua programação através de temáticas e disciplinas pouco convencionais ao mundo da arte como uma tática de atração de grupos pouco privilegiados na tradicional história da arte. A reestruturação dos modelos expográficos para iniciativas mais laboratoriais, em que as linguagens híbridas promovem um engajamento mais afetivo e lúdico do espectador com a proposta artística, ou seja, centradas na reconfiguração do lugar do espectador, coloca em xeque o modo de se relatar, descrever, estudar e analisar o desenvolvimento das expografias. A partir das particularidades da minha experiência ao articular uma escrita etnográfica como forma para produção de conhecimento sobre estes empreendimentos, é possível entrever alternativas abordagens metodológicas ao público através do posicionamento do pesquisador como público, antes de tudo.

\section{Referência bibliográficas}

BECKER, Howard. Uma teoria da ação coletiva. Rio de Janeiro: Editora Zahar, 2009.

BEIGUELMAN, Giselle. Do cubo branco à caixa preta. Revista Eletrônica Trópico, seção Novo Mundo, agosto 2004. Disponível em: http://www2.vol.com.br/tropico/novomundo 92581 1.shl Acesso em 12 de novembro de 2018.

BISHOP, Claire. Radical museology or what is 'contemporary' in museums of contemporary art. London, UK: Koenig Books, 2013.

BOURDIEU, Pierre. As regras da arte: gênese e estrutura do campo literário. São Paulo: Companhia das Letras, 1996.

BUSKIRK, Martha. Context as Subject. In: The contingent object of contemporary art. Cambridge, MA; London, UK: The MIT Press, 2003.

CLIFFORD, James. Sobre a autoridade etnográfica. In: A experiência etnográfica: antropologia e literatura no século XX. Rio de Janeiro: Editora UFRJ, 2002.

COOK, Sarah. Immateriality and Its Discontents: An Overview of Main Models and Issues for Curating New Media. In: PAUL, Christiane (org.). New Media in the White Cube and Beyond: Curatorial models for digital art. Oakland, California: University of California Press, 2008.

COOK, Sarah; BARKLEY, Aneta. The Digital Arts In and Out of the InstitutionWhere to Now? PAUL, Christiane (org.). A companion to digital art. Coleção Wiley Blackwell Companions to Art History. Hoboken, UK: John Wiley \& Sons Inc., 2016. 
CORNWELL, Regina. Interactive art: touching the "body in the mind". Discourse, v. 14, n. 2, Performance issue: Happening, Body, Spectacle, Virtual Reality. Wayne State University, US: spring 1992.

DABUL, Lígia. O público em público: práticas e interações sociais em exposições de artes plásticas. 333 fl. Tese (Doutorado em Sociologia) - Programa de PósGraduação em Sociologia, Universidade Federal do Ceará, Fortaleza, 2005.

Museus de grandes novidades: centros culturais e seu público. Horizontes Antropológicos, ano 14, n. 29. Porto Alegre, 2008.

DA MATTA, Roberto. O ofício do etnólogo: ou como ter anthropological blues. Rio de Janeiro: Boletim do Museu Nacional, seção Antropologia, $n^{\circ} 27$, maio de 1978.

FAVRET-SAADA, Jeanne. Ser afetado. Tradução de Paula Siqueira. Revisão Técnica de Tânia Stolze Lima. Cadernos de campo, n. 13, 2005.

FRIELING, Rudolf. Participatory Art: Histories and experiences of display. In: PAUL, Christiane (org.). A companion to digital art. Coleção Wiley Blackwell Companions to Art History. Hoboken, UK: John Wiley \& Sons Inc., 2016.

GEERTZ, Clifford. Uma descrição densa: por uma teoria interpretativa da cultura. In: $A$ interpretação das culturas. Rio de Janeiro: Editora Guanabara Koogan, 1989.

HEINICH, Nathalie. The Pompidou Centre and its public: the limits of a Utopian site. LUMLEY, Robert (org.). The museum time machine. London; New York: Routledge, 1988.

- From museum curator to exhibition auteur. In: GREENBERG, Reesa; FERGUSON, Bruce; et al. (org.). Thinking about exhibitions. London: Routledge, 2007.

HOOPER-GREENHILL, Eilean. Counting visitors or visitors who count? In: LUMLEY, Robert (org.). The museum time machine. London; New York: Routledge, 1988.

MAGNANI, José Guilherme. Quando o campo é a cidade: fazendo antropologia na metrópole. In: Magnani, José Guilherme C. \& Torres, Lilian de Lucca (Orgs.) Na Metrópole - Textos de Antropologia Urbana. EDUSP, São Paulo, 1996.

MANOVICH, Lev. The language of new media. Cambridge, MA; London, UK: The MIT Press, 2001.

MOULIN, Raymonde. O mercado de arte: mundialização e novas tecnologias. Porto Alegre: Zouk, 2007.

MUNIAGURRIA, Lorena de. "Ganhar o olhar": Estudo antropológico de ações de mediação em exposições de artes visuais. Dissertação (Mestrado em Ciências Sociais) Programa de Pós-Graduação em Antropologia Social, Universidade Federal do Rio Grande do Sul. Porto Alegre, 2006.

O'DOHERTY, Brian. No interior do cubo branco: a ideologia do espaço de arte. São Paulo: Editora Martins Fontes, 2002.

QUARANTA, Domenico. A few notes on curating. In: Beyond New Media Art. Brescia, LINK Editions, 2013. ISBN 978-1-291-37697-5. 
TEIXEIRA COELHO, José. Dicionário Crítico de Política Cultural. São Paulo: Editora lluminuras LTDA., 1997.

RANCIÈRE, Jacques. O espectador emancipado. São Paulo: Editora Martins Fontes WMF, 2012.

RINEHART, Richard. One of Us! On the Coupling of New Media Art and Art Institutions. PAUL, Christiane (org.). A companion to digital art. Coleção Wiley Blackwell Companions to Art History. Hoboken, UK: John Wiley \& Sons Inc., 2016.

SHANKEN, Edward. Contemporary art and new media: Digital divide or hybrid discourse? In: PAUL, Christiane (org.). A companion to digital art. Coleção Wiley Blackwell Companions to Art History. Hoboken, UK: John Wiley \& Sons Inc., 2016.

WILLIAMS, Raymond. Cultura. São Paulo: Brasiliense, 1992. 